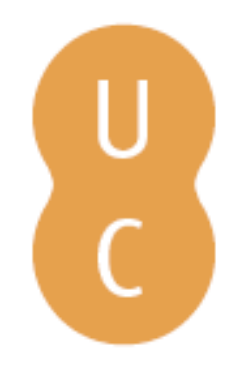

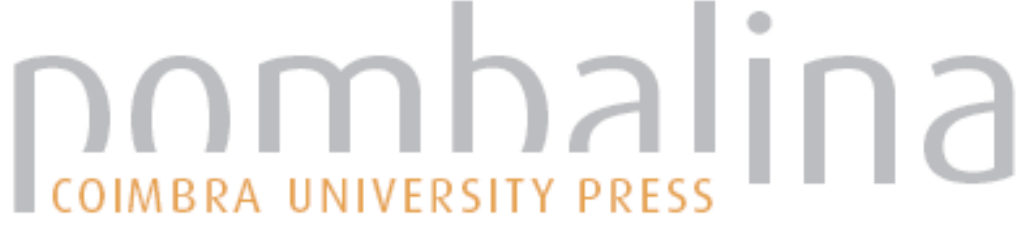

\section{Global burned area maps from MERIS}
Autor(es):
Alonso-Canas, Itziar; Chuvieco, Emilio
Publicado por: Imprensa da Universidade de Coimbra
URL persistente:
URI:http://hdl.handle.net/10316.2/34313
DOI:
DOI:http://dx.doi.org/10.14195/978-989-26-0884-6_86

Accessed : $\quad$ 26-Apr-2023 11:11:57

A navegação consulta e descarregamento dos títulos inseridos nas Bibliotecas Digitais UC Digitalis, UC Pombalina e UC Impactum, pressupõem a aceitação plena e sem reservas dos Termos e Condições de Uso destas Bibliotecas Digitais, disponíveis em https://digitalis.uc.pt/pt-pt/termos.

Conforme exposto nos referidos Termos e Condições de Uso, o descarregamento de títulos de acesso restrito requer uma licença válida de autorização devendo o utilizador aceder ao(s) documento(s) a partir de um endereço de IP da instituição detentora da supramencionada licença.

Ao utilizador é apenas permitido o descarregamento para uso pessoal, pelo que o emprego do(s) título(s) descarregado(s) para outro fim, designadamente comercial, carece de autorização do respetivo autor ou editor da obra.

Na medida em que todas as obras da UC Digitalis se encontram protegidas pelo Código do Direito de Autor e Direitos Conexos e demais legislação aplicável, toda a cópia, parcial ou total, deste documento, nos casos em que é legalmente admitida, deverá conter ou fazer-se acompanhar por este aviso.

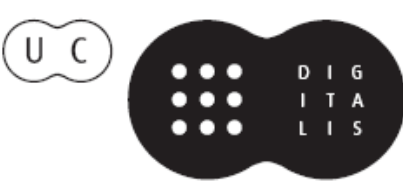




\section{ADVANCES IN}

Forest Fire

\section{RESEARCH}

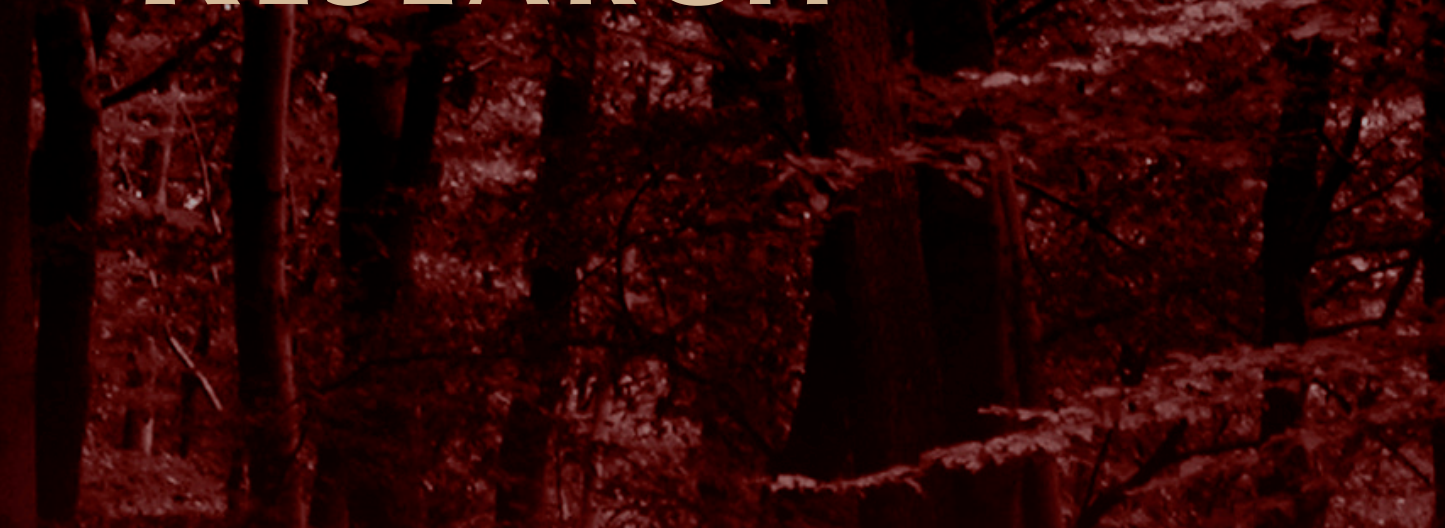

\section{DOMINGOS XAVIER VIEGAS}

\section{EDITOR}




\title{
Global burned area maps from MERIS
}

\author{
Itziar Alonso-Canas, Emilio Chuvieco
}

Environmental Remote Sensing Research Group, Universidad de Alcalá, Colegios 2, Alcalá de

Henares, Spain; e-mail: itziar.alonsoc@uah.es, emilio.chuvieco@uah.es

\begin{abstract}
Biomass burning is a global scale phenomenon that affects annually around 3.5 million Km2. This phenomenon has a very critical relevance for vegetation dynamics, atmospheric emissions and carbon budgets, increasingly affecting human lives and property, particularly in catastrophic conditions (heat waves, drought, strong winds). Properly characterizing burned areas on a global scale has become a relevant factor when studying these processes. The Fire CCI project, in the framework of the ESA's Climate Change Initiative, aims at providing consistent time series of burned areas (BA) globally, over the period 1995 to 2009. Global BA products are obtained by merging information from three sensors: the ATSR series, VEGETATION and MERIS. In this case, the algorithm developed to obtain burned areas from the MERIS sensor will be presented. The MERIS BA algorithm is based on MERIS reflectance bands, spectral indices and both post-fire and multi-temporal analysis controlled by HS locations. BA detection is performed in a two phase process: the first one aims to detect seed pixels while the second one will develop contextual criteria around these seed pixels. Global BA maps have been obtained with the MERIS algorithm for years 2006 to 2008.
\end{abstract}

Keywords: Burned Area, Climate Change, MERIS

\section{Introduction}

Fire is a key component of the carbon cycle affecting greenhouse gases and aerosols emissions to the atmosphere (Andreae and Merlet 2001; van der Werf, Randerson et al. 2010), as well as global vegetation dynamics (Kloster, Mahowald et al. 2012; Thonicke, Spessa et al. 2010). Therefore, it becomes highly critical to monitor fires on a global scale and to estimate their impacts through global climate model simulations, biogeochemical models and dynamic global vegetation models.

Monitoring areas affected by biomass burning has been performed over the last decades using a wide variety of sensors, including very high-spatial resolution such as Ikonos for fine scales (Kachmar and Sanchez-Azofeifa 2006), high spatial resolution sensors such as Landsat-TM/ETM+ or SPOT-HRV for regional areas (Bastarrika, Chuvieco et al. 2011b; Pu and Gong 2004) and medium resolution sensors for continental to global studies (Chang and Song 2009; Chuvieco, Opazo et al. 2008; Giglio, Randerson et al. 2010; Roy, Boschetti et al. 2008; Tansey, Grégoire et al. 2008).

In the context of the fire_cci project, the goal of this work is to present a global BA algorithm specifically designed for the ENVISAT MERIS sensor. MERIS was mainly designed for ocean colour applications, as it provides high spectral resolution in the range of the blue to the near infrared regions (Gower and Borstad 2004). The application of MERIS data to fire applications is scarce: identification of smoke plumes (Huang and Siegert 2004), discrimination of burn severity (De Santis and Chuvieco 2007; Roldan-Zamarron, Merino-De-Miguel et al. 2006). Mapping BA with MERIS has only been performed at regional level (Oliva, Martin et al. 2011) using different vegetation indices while (González-Alonso 2009) combined fire hotspots from MODIS and NIR reflectance values from MODIS and MERIS imagery.

The potentials of MERIS for improving current information of BA rely on its greater spatial resolution, complementing other existing global BA products, particularly in areas where under or overestimations have been shown (Chang and Song 2009), thus reducing the uncertainty of current collections. Furthermore, this sensor has a follow up version on the OLCI (Ocean and Land Colour 
Instrument) on board Sentinel 3, scheduled for launch in 2015 as part of the EC Copernicus programme.

\section{Methods}

The design of a global BA algorithm requires considering the great diversity of biomass burning conditions worldwide. The most extended approaches for mapping BA can be classified in two groups: those that use the thermal contrast of active fires (hot spots, HS) from the surrounding background (Giglio, van der Werf et al. 2005), and those based on reflectance changes caused by burning effects (changing of leaf and soil colour, leaf losses, char, etc) (Bastarrika, Chuvieco et al. 2011a; Roy, Jin et al. 2005). The former approach is more reliable because thermal radiance increases exponentially with temperature, while reflectance changes are more subtle. However, thermal signal lasts very shortly (minutes to hours), while the fires are active, where as post-fire reflectance changes are more lastly (days to years). In addition, BA mapping based on active fires only implies a sample of the total area burned (what is burning when the satellite observes the area), while reflectance changes cover the whole area affected by the fire.

Considering the pros and cons of each approach, several authors have proposed hybrid algorithms, where HS information is used to guide somehow the analysis of reflectance changes in the discrimination of BA, particularly to avoid commission errors (i.e. reflectance changes caused by nonfire causes, such as crop harvest, seasonal flooding, or topographic shade). After analyzing the spectral and temporal characteristics of MERIS, it was decided to follow a similar approach for developing the global BA algorithm, using a synergetic use of HS information derived from MODIS thermal data and temporal trends of MERIS reflectance bands. The hypothesis is that (Kaufman and Justice 1998) the combination of spectral reflectance information with active fires to identify BA should provide a more reliable discrimination of BA. In order to consider a proper balance between omission and commission errors, the algorithm includes two different phases (Chuvieco, Englefield et al. 2008): seed identification, which aims to minimize commission errors by selecting only those pixels more clearly burned, and contextual analysis, which applies region growing analysis to improve the delimitation of burned patches.

The algorithm was developed and tested in 10 different study sites, which were selected to take into account the diversity of burning conditions worldwide, including different biomes and fire regimes (Figure 1). (Olson, E. Dinerstein et al. 2001)

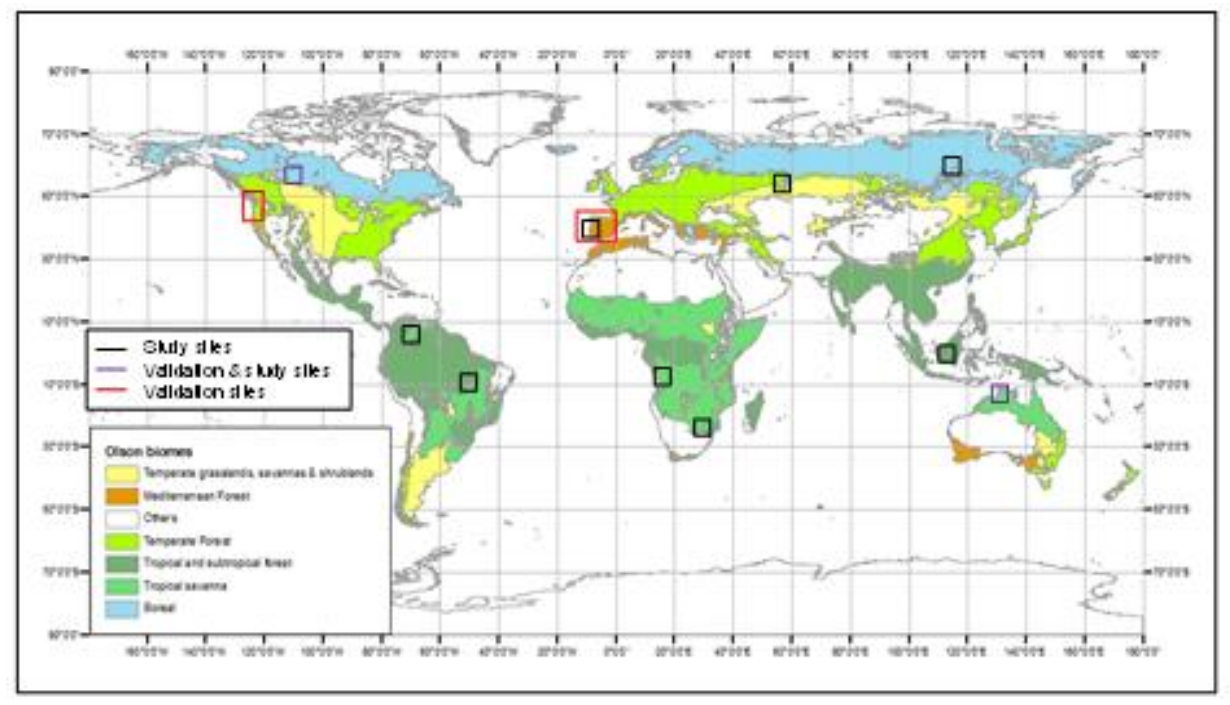

Figure 1. Study sites selection 


\subsection{Generation of corrected reflectances and spectral indices}

Corrected MERIS reflectances were received from Brockman Consult. The pre-processing chain was based on the one developed for the Land CCI project with modifications to obtain daily reflectances instead of weekly composites as was required by this project. Geometric correction is obtained through the AMORGOS (Accurate MERIS Ortho Rectified Geo-location Operational Software), improving MERIS FR geolocation better than 70 RMS. Calibration and smile correction are also performed, as well as land water delineation, cloud screening and atmospheric correction. More details of these processes can be found in the ATBD from the Land CCI project (http://www.esa-landcover-cci.org/). The surface directional reflectances are floats between 0 and 1.0. As an output from the pre-processing, additional information layers are included with the MERIS images. Standard error associated to each band is provided. The angles are taken from the respective MERIS L1B input, sun and zenith viewing angles and sun and azimuth angles are provided in degrees. Also, a status layer is provided, with values 1 (clear land), 3 (snow/ice), or 0 (i.e. water, cloud, no observation).

In order to improve performance of the algorithm, the corrected reflectances were gridded into 10x10 degrees tiles (3600x3600 pixels at MERIS spatial resolution). These tiles were the input files for all processes of the BA algorithm.

The NIR region was selected as main input for the MERIS algorithm, since this spectral band has been shown to be highly sensitive to recent burns, especially when pre-fire fuel loadings are high and combustion produces large amounts of charcoal that are deposited on the ground (Pereira, Sa et al. 1999). Both green and dry vegetation have substantially higher reflectance than recent burns in the NIR. The suitability of this band to detect burned areas has been shown in previous studies (Chuvieco, Martín et al. 2002; Koutsias and Karteris 2000; Trigg and Flasse 2001).

In addition to the NIR band, we computed the Global Environmental Monitoring Index (GEMI) (Pinty and Verstraete 1992), which was proven the best performing to detect burned areas among the spectral indices based on the red-NIR space (Barbosa, Stroppiana et al. 1999; Chuvieco 2002; Chuvieco, Englefield et al. 2008; Martín, Gómez et al. 2005; Pereira, Sa et al. 1999). GEMI was computed as follows:

$$
\begin{aligned}
& G E M I=\frac{\eta(1-0.25 \eta)-\left(\rho_{R}-0.125\right)}{\left(1-\rho_{R}\right)} \\
& \eta=\frac{2\left(\rho_{N I R}{ }^{2}-\rho_{R}{ }^{2}\right)+1.5 \rho_{\text {NIR }}+0.5 \rho_{R}}{\left(\rho_{R}+\rho_{N I R}+0.5\right)},
\end{aligned}
$$

where $\rho_{\text {NIR }}$ is the reflectance in the NIR (MERIS Band 10) and $\rho_{R}$ is the reflectance in the Red (MERIS Band 8).

The selection of MERIS Bands $8(673.75 \mathrm{~nm}$ to $688.75 \mathrm{~nm})$, and $10(746.25 \mathrm{~nm}$ to $761.25 \mathrm{~nm})$, was based on the results from (Oliva, Martin et al. 2011), which showed a better sensitivity of the short NIR bands (bands 9 to 12) over the long NIR bands (bands 13 to 15) to discriminate BA areas. Following their conclusions, band 10 was used for the NIR region and bands 8 and 10 for computing the GEMI index.

\subsection{Generation of composites}

Temporal resolution of input data is quite relevant to build a global BA algorithm, since the analysis of post-fire reflectance may be easily contaminated by clouds or be affected by quick vegetation recovery. Therefore, the number of observations is a limiting factor for detecting fires in areas where images are not available for long periods of time. In order to improve spatial coherence of areas with low temporal continuity, monthly composites of near infrared reflectance (NIR) were generated. These composites were the basis for the two phases of BA detection. Composites were built for each month by selecting NIR information from a bi-monthly time space. This helps ensuring continuity in fire detection and is particularly relevant when a fire occurs in the final dates of a month. 
The criteria for generating the monthly NIR-GEMI composites were chosen as to emphasize the sensitivity of the outputs to the burned signal. Two criteria were used: maximize the contiguity to fire dates and minimize the NIR signal. Since HS provide a very accurate estimation of burning dates (Boschetti, Roy et al. 2010), we first generated the composites selecting for each location the closest date to the closest HS. For doing so, a Thiessen matrix was created for each period, computing for each pixel the closest HS coordinates and labelling it with the date of that HS. For the Thiessen matrix we also considered HS located within a buffer of 0.5 degrees around the edges of each tile. This option mitigated potential continuity problems between tiles, when for instance a fire was in the edge between tiles.

The second compositing criteria selected minimum NIR reflectance values of the temporal series. However, since low NIR can be caused also for other reasons (cloud or topographic shadows, for instance), instead of selecting the minimum NIR of the 60 day period, we chose the first minimum after the date stored in the Thiessen HS matrix, as this would select a more immediate value to the post-fire burn reflectance. If no minima exist after that date, then the second minimum was chosen. In addition to the monthly post-fire composites, an annual reference composite was created to help the contextual phase of the algorithm. This annual composite was obtained as the per pixel difference between the annual maximum GEMI value per year and the monthly GEMI composite. The former was created to obtain an estimation of the maximum annual greenness of each pixel time series. The expected change between that maximum value and the post-fire value (the GEMI monthly composite) should be the highest, which should emphasize post-fire spectral changes.

\subsection{Seed selection}

The first part of the seed selection focused on generating statistics of burned and unburned areas for each tile, based on the composite NIR values and HS distribution. Since burned conditions may be very diverse worldwide, we tried to obtain regional-oriented NIR thresholds, which could be tailored to different post-fire reflectance conditions. Cumulative distribution functions (CDF) were created to establish discrimination thresholds of NIR values that would be better adapted regionally to separate between burned and unburned categories.

The burned pixels to obtain the CDF of BA were obtained from the information provided by the MODIS HS to select the minimum NIR values. Since HS have an original resolution of 1000x $1000 \mathrm{~m}$, instead of assuming that all MERIS pixels covered by the HS are active fires, we assumed that the potential active fire (PAF) was more likely located where the MERIS NIR value was lowest in the $3 \times 3$ window around the HS. To avoid commission errors, we introduced an additional temporal change constrain, and accepted only those PAF where NIR values were lower than in the previous period. Otherwise, the minimum NIR values were not considered PAF to build the CDF of the burned category. The CDF of the unburned category was generated from the values of those pixels that did not have any HS in a 64x64 pixel matrix and were not detected by the BA algorithm in the previous months.

Specific discrimination thresholds were established for each tile and month. In order to compute them, the NIR threshold value of the burned category (TB) was defined as the decile of the burned pixels $\mathrm{CDF}$ that intersected the first decile of the CDF of unburned pixels (NIR values of burned pixels were expected to be lower than those of unburned ones) (fig 2). The more separated the CDFs between burned and unburned categories are, the higher the decile to define the burned category, as there are less chances of confusion with unburned category. On the opposite, the closer the CDFs the more pixel values are shared by the burned and unburned distributions, and therefore a more restrictive condition was chosen. It was considered a good discrimination between burned and unburned CDF when the threshold was established at 7 or more decile value, and bad discrimination otherwise. This classification was later used for phase 2 of the algorithm.

Seed pixels of burned category were selected based on three criteria: 
a) The NIR value was lower than the TB for each tile and period.

b) At least one PAF should be found in a neighbour 9x9 matrix;

c) NIR value for month $\mathrm{n}$ should be lower than NIR of month $\mathrm{n}-1$.
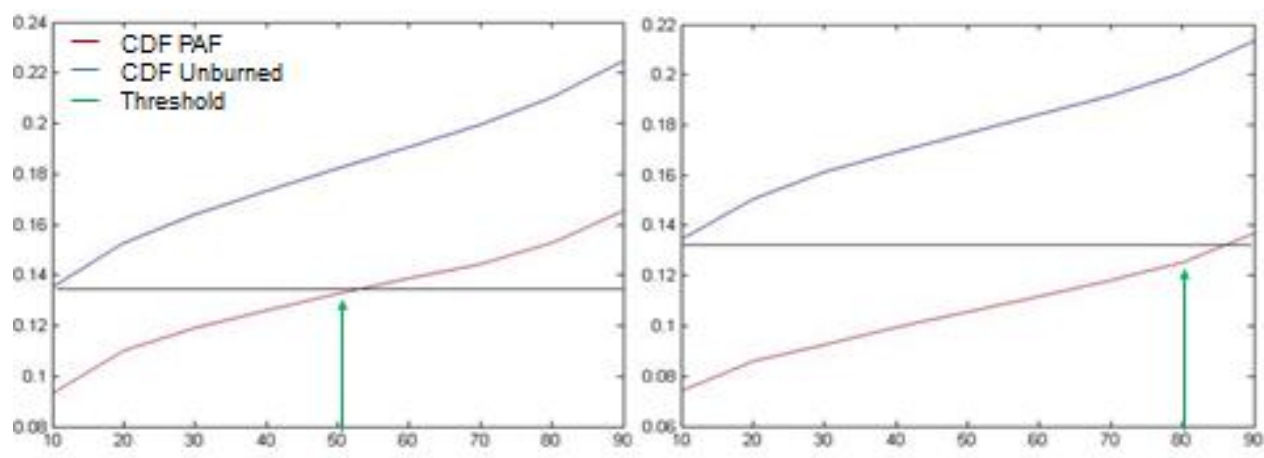

Figure 2. Threshold based on decile 10 of the unburned for a case with worse (left) and better (right) separation between classes for the Australian study site, correspondent to July \& October 2005 respectively

\subsection{Region growing}

Contextual algorithms have been previously used for BA mapping (Bastarrika, Chuvieco et al. 2011b; $\mathrm{Pu}$, Li et al. 2007). The goal of these algorithms is to reduce omission errors from the seed phase, while avoiding increasing commission errors. One of the critical issues to obtain a good performance of these algorithms for BA mapping relies on obtaining a sound method to stop the region growing process (Zhang, Pavlic et al. 2005).

Once the seeds were obtained, a region growing mechanism was applied to refine the characterization of burned patches. Only pixels surrounding the BA seeds were analyzed. This second phase of the BA algorithm included three conditions. These three conditions tried to account for a proper balance between extending the burned patches and avoiding commission errors. They were analyzed recursively around each seed pixel until their neighbour pixels did not meet them, which implied the end of the region growing process. If the criteria were met, the pixel will be included as seed and also its surrounding pixels will be studied. These criteria were:

a) The NIR threshold values were reviewed for this phase. If the TB was based on decile 6 or lower, it was assumed that the discrimination between categories is not good enough to increase the threshold. In this case the value was kept as it was for the seed phase. Otherwise, we assumed a better discrimination of burned and unburned categories and therefore, the NIR thresholds were increased for the region growing process up to the TB found at decile 9.

b) The decrease in NIR in burned pixels should be more negative than the threshold NIR decrease of unburned pixels. To define this new threshold we only considered those pixels more clearly unburned. We selected the first decile of the unburned CDF that has a higher value than decile 9 of the burned curve. For all pixels that satisfy this condition the difference with the composite from the previous month was computed. A new curve is built with these values. The minimum drop is defined as the percentile 90 of this curve.

c) Finally, the third condition was based on detecting the vegetation loss as a result of fire, based on the differences in GEMI values between the target monthly composite and the annual GEMI composites. This criterion was defined as 0.9 times the difference found in the GEMI value between the target pixel and those labelled as burned (either seeds or neighbour detected burns). 


\section{Results and validation}

Three years of MERIS data (2006 to 2008) were processed with the described algorithm. Global BA obtained for years 2006, 2007 and 2008 was 3650268, 3772086 and 362327 km2 respectively. Figure 3 shows the BA obtained for year 2008.

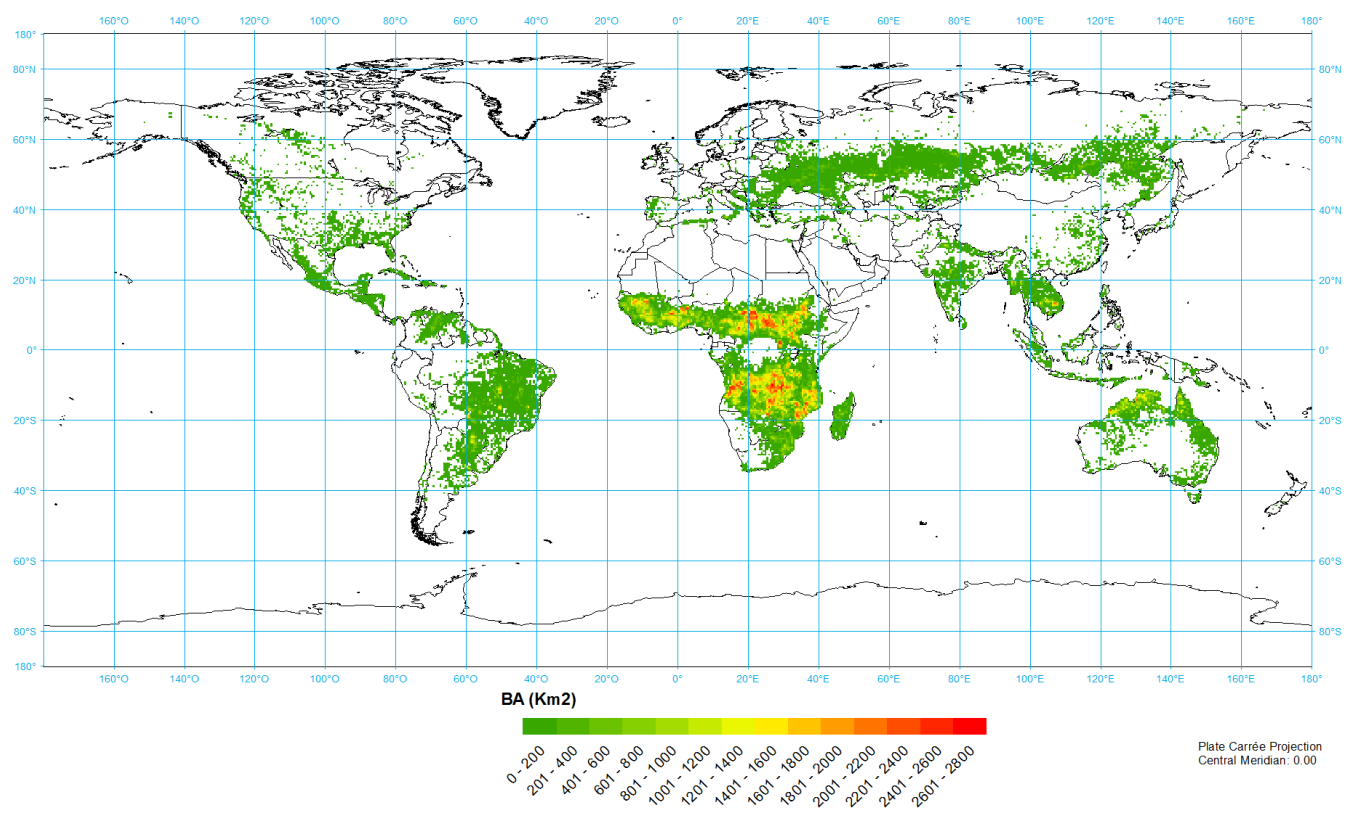

Figure 3. Global BA from MERIS in 2008

A complete global and temporal validation strategy has been developed within the Fire-CCI project. In this framework, a validation of the MERIS BA product performed with a LANDSAT validation dataset was performed. Results can be found in Padilla et al, 2014 (in preparation). The validation presented here is based on the use of perimeters obtained from different agencies and aims at validating the product in larger areas. The validation was performed for the 3 years where MERIS BA product is currently available (2006 to 2008).

Four areas were chosen:

- Canada: perimeters were downloaded from the Canadian Wildland Fire information System (cwfis.cfs.nrcan.gc.ca/ha/nfdb/). The Canadian National Fire Databse (CNFDB) is a collection of forest fire data from various sources, provided by Canadian fire management agencies (provinces, territories, and Parks Canada). The area designed to perform the validation is the Canadian study site (Figure 1). MERIS BA product and perimeters from the fire information system were reprojected to UTM.

- Australia: the Australian perimeters were downloaded from the North Australian Fire Information database (www.firenorth.org.au/nafi2/). Also the study site area was chosen to perform the validation (Figure 1). Both MERIS and perimeter databases were projected to UTM. Fire scars are sourced from the Darwin Centre for bushfires research at Charles Darwin University (for NT and northern WA fire scars) and Cape York Peninsula sustainable futures (for Queensland). They are obtained from $250 \mathrm{~m}$ MODIS imagery. Two images are used to map the affected areas, by using segmentation and visual interpretation (http://www.firenorth.org.au/nafi2/about/faq.pdf). 
- The Californian perimeters were downloaded from the Fire and Resource Assessment program (FRAP) webpage (frap.fire.ca.gov). Fire perimeters information is obtained by several agencies. The validation site chosen covers an area of $572000 \mathrm{~km} 2$ (Figure 1). MERIS data were reprojected to the perimeters database projection (alberts_conic_equal_area).

- Iberian Peninsula Perimeters were obtained from the European Forest Fire Information System (EFFIS). EFFIS makes use of satellite imagery acquired with MODIS. The area was selected to include the Iberian Peninsula, as shown in Figure 1. MERIS data were reprojected to the perimeters projection, standard European spatial reference system ETRS-LAEA, ETRS89, Lambert azimuthal equal area.

Validation results are shown in Table 1 for the 4 areas under study. Through the years same tendencies and range of commission and omission errors are identified. Overall there is a tendency towards omission for the 3 years. Australia shows higher omission errors. The Californian validation site shows a higher balance between omission and commission except for year 2008. The Canadian area has higher omission values, where as in the Iberian Peninsula the MERIS BA algorithm tends to overestimate the BA leading to higher commission errors.

Table 1. Validation for 4 areas, years 2006 to 2008.

\begin{tabular}{|l|l|l|l|l|l|l|l|l|l|}
\hline & \multicolumn{4}{|l|}{2006} & \multicolumn{2}{l|}{2007} & \multicolumn{2}{l|}{2008} & \\
\hline & CE & OE & OA & CE & OE & OA & CE & OE & OA \\
\hline Australia & 0.0854 & 0.4251 & 0.7887 & 0.1105 & 0.4291 & 0.8075 & 0.1416 & 0.4488 & 0.8498 \\
\hline California & 0.3256 & 0.3409 & 0.9971 & 0.3538 & 0.3333 & 0.9955 & 0.1706 & 0.4568 & 0.9953 \\
\hline Canada & 0.3062 & 0.4669 & 0.9809 & 0.0322 & 0.5597 & 0.9924 & 0.1412 & 0.7126 & 0.9807 \\
\hline SP \& PT & 0.4400 & 0.2363 & 0.9984 & 0.6545 & 0.3954 & 0.9994 & 0.8300 & 0.6327 & 0.9997 \\
\hline
\end{tabular}

Figure 4 shows cumulative distribution curves that relate the number of fires detected per fire size for both the validation dataset (dotted line) and the MERIS one (black line) for year 2008. In the case of the validation datasets, perimeters are already identified by a number that differs for each perimeter. In the case of MERIS, perimeters were obtained by assuming that the pixels burned are part of the same perimeter when the dates between neighbour pixels do not differ in more than 15 days. In the Australian site, both NAFI and MERIS show the same tendency. Omission errors found in the validation exercise are shown by the fact that the MERIS line follows under the NAFI one for all fire sizes. For the other 3 validation sites the number of fires detected by MERIS is higher for small fire sizes where as it becomes lower for bigger size patches. This trend is especially clear for the Canadian site. Similar results and behaviour were obtained for years 2007 and 2006. 

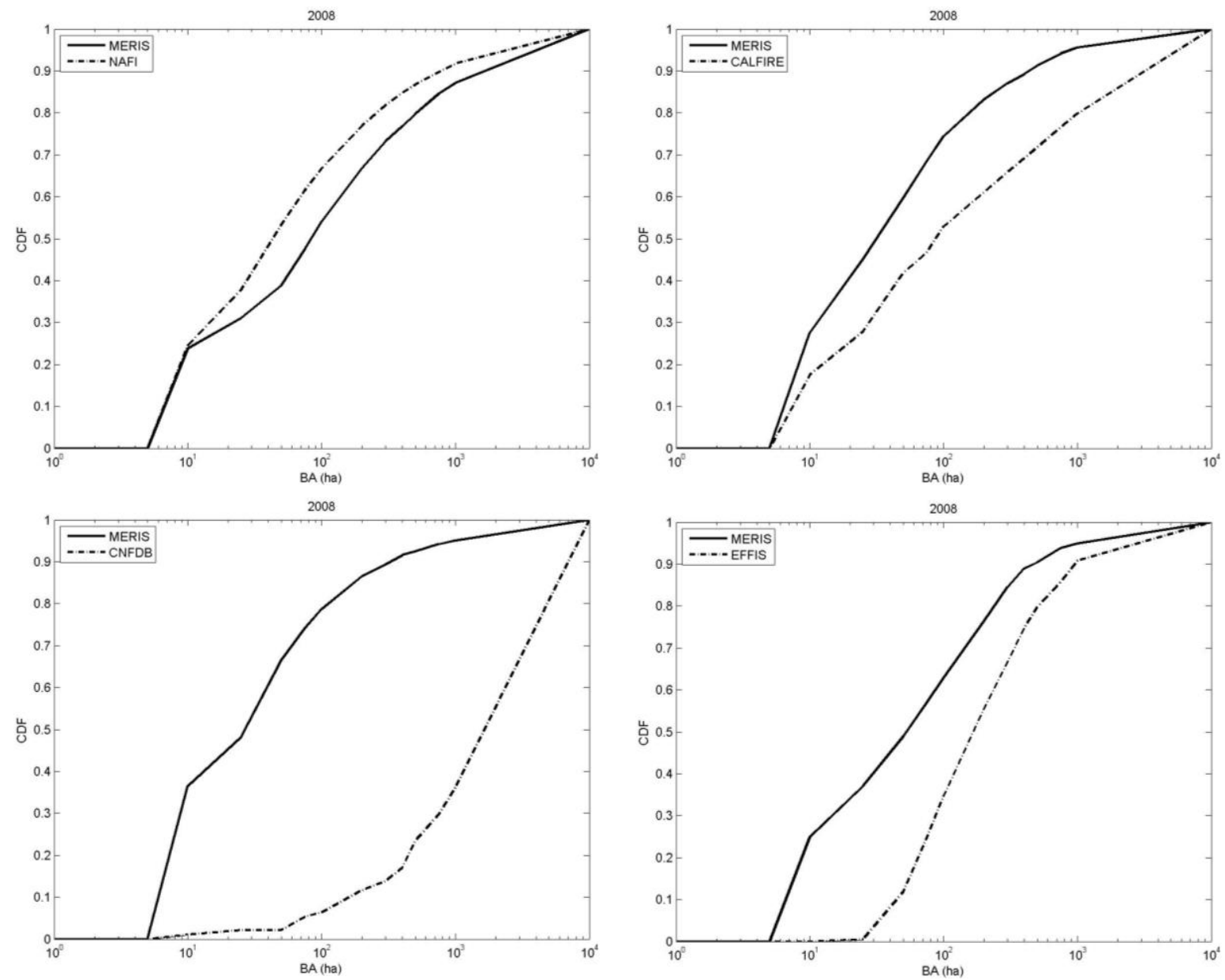

Figure 4. Fire size classification for 2008

We separated the BA by ecosystem, following the classification defined in (Giglio, Loboda et al. 2009). Results are shown in Table 2. The areas with higher fire activity are AUS, BOAS, CEAS, NHAF, SHAF, SHSA showing similar tendencies for the 3 years. When comparing the product globally to the MDC 64 (Table 2) results show that MERIS estimates more BA than MCD64 for the 3 years where the comparison has been performed, having the largest difference in 2008. Results are consistent in the order of magnitude for all regions. For 9 regions (CEAM, CEAS, EURO, NHAF, NHSA, SEAS, SHAF, SHSA, TENA) MERIS estimates are higher or in the same order as the GFED ones. In these cases, the trend is consistent between years, i.e. if a BA value increases from one year to the next in the MERIS case, the same behaviour occurs in the GFED. In another 3 regions (AUS, BONA and MIDE) BA MERIS estimates are lower or in the same order than GFED. There are only 2 regions where results are less consistent between the two products (BOAS and EQAS). In BOAS, 2006 has an order of magnitude higher in MERIS estimates, where as 2007 is higher than GFED but in the same range and 2006 is lower than GFED but in the same order. In EQAS 2006 has lower estimates than GFED, where as 2007 and 2008 have higher values. 
Table 2. MERIS and GFED values for years 2006 to 2008 separated by ecoregion.

\begin{tabular}{|l|l|l|l|l|l|l|}
\hline & 2008 & & 2007 & & 2006 & \\
\hline ECO REGION & GFED & MERIS & GFED & MERIS & GFED & MERIS \\
\hline AUST & 266319 & 223018 & 487099 & 374883 & 530913 & 339800 \\
\hline BOAS & 120490 & 106510 & 32399 & 43208 & 43288 & 113926 \\
\hline BONA & 14465 & 6350 & 15458 & 9656 & 19117 & 13133 \\
\hline CEAM & 11648 & 16153 & 10611 & 16085 & 12571 & 17256 \\
\hline CEAS & 139938 & 171311 & 124669 & 151462 & 175395 & 172419 \\
\hline EQAS & 4239 & 6068 & 4776 & 6370 & 26826 & 15085 \\
\hline EURO & 5367 & 12624 & 9655 & 14450 & 4771 & 9891 \\
\hline MIDE & 6036 & 6945 & 11770 & 8481 & 9015 & 8637 \\
\hline NHAF & 1176668 & 1275054 & 1234422 & 1236476 & 1151535 & 1227041 \\
\hline NHSA & 17754 & 24726 & 25153 & 27424 & 14925 & 15591 \\
\hline SEAS & 69744 & 99912 & 98740 & 113824 & 59303 & 87737 \\
\hline SHAF & 1315416 & 1473301 & 1242137 & 1396252 & 1221849 & 1395718 \\
\hline SHSA & 133827 & 188187 & 338357 & 338256 & 124969 & 204359 \\
\hline TENA & 14524 & 13118 & 26641 & 35257 & 24214 & 29676 \\
\hline GLOBAL & 3296434 & 3623277 & 3661888 & 3772086 & 3418690 & 3650268 \\
\hline
\end{tabular}

\section{Discussion and conclusion}

MERIS BA estimates are higher than the ones obtained by other collections such as GFED for the 3 years that have been processed, but remain in the same range. In 2 of these areas (AUS, BONA) validation was performed and results showed a tendency towards omission for the 3 years tested. More detailed identification of omission and commission errors will be available soon in Padilla et al, 2014. but from this preliminary study there seems to be an underestimation of BA in certain regions. There are 2 possible reasons for this:

- Omission inherent to the HS: as shown in (Hantson, Padilla et al. 2013), commission errors in the MOD14 product tend to be small, but omission errors can be significant, especially for some areas (South Africa, Colombia, Australia).

- Conditions too restrictive in both seed and growing phases. In the seed phase the algorithm does not consider all HS as seeds, pixels that do not satisfy the conditions detailed in the previous sections will not be classified as seeds. Filtering out some of the HS should not be a significant problem for large fires, since pixels around the detected PAFs will also be studied. Nevertheless, excessive filtering can become relevant for smaller fires, or in areas where there are less HS, as all HS could be filtered out in the seed phase, leading to non detection of the fire. In the growing phase conditions could be too restrictive particularly for some regions. In this case, larger fires will be considered smaller, and if there are several seeds for the fire this will probably lead to fragmentation of fires. This will lead to an over estimation of smaller number of perimeters in cases where the same fire is fragmented. This could explain the results shown in Figure 4, where smaller fires were more abundant that in the database due to the fact that the fire might be fragmented, and it was considered as more than one perimeter. Although when designing the algorithm the aim was to make it tailored for each region, the growing conditions might not be optimal for all types of land cover and ecosystems.

An algorithm to estimate burned areas on a global scale for the MERIS sensor has been presented. It is an hybrid algorithm that makes use of thermal and spectral information to detect fire scars. It is based on a two steps process: seed and growing phases. Results have been obtained for 3 years of data, and show consistency with other BA collections such as GFED. According to preliminary validation 
results, there is a tendency towards omission. Future versions of the algorithm will consider these findings to refine the BA estimates.

\section{References}

Barbosa PM, Stroppiana D, Gregoire JM, Pereira JMC (1999) An assessment of vegetation fire in Africa (1981-1991): Burned areas, burned biomass, and atmospheric emissions. Global Biogeochemical Cycles 13, 933-950.

Bastarrika A, Chuvieco E, Martin MP (2011a) Automatic Burned Land Mapping From MODIS Time Series Images: Assessment in Mediterranean Ecosystems. IEEE Transactions on Geoscience and Remote Sensing 49, 3401-3413.

Bastarrika A, Chuvieco E, Martín MP (2011b) Mapping burned areas from Landsat TM/ETM+ data with a two-phase algorithm: balancing omission and commission errors. Remote Sensing of Environment 115, 1003-1012.

Boschetti L, Roy DP, Justice CO, Giglio L (2010) Global assessment of the temporal reporting accuracy and precision of the MODIS burned area product. International Journal of Wildland Fire 19, 705-709.

Chang D, Song Y (2009) Comparison of L3JRC and MODIS global burned area products from 2000 to 2007. Journal of Geophysical Research 114, 10.1029/2008JD11361.

Chuvieco E (2002) 'Teledetección Ambiental: La observación de la Tierra desde el Espacio.' (Ariel Ciencia: Barcelona)

Chuvieco E, Englefield P, Trishchenko AP, Luo Y (2008) Generation of long time series of burn area maps of the boreal forest from NOAA-AVHRR composite data. Remote Sensing of Environment vol. 112, 2381-2396.

Chuvieco E, Martín MP, Palacios A (2002) Assessment of different spectral indices in the red-nearinfrared spectral domain for burned land discrimination. International Journal of Remote Sensing 23, 5103-5110.

Chuvieco E, Opazo S, et al. (2008) Global Burned Land Estimation in Latin America using MODIS Composite Data. Ecological Applications 18, 64-79.

De Santis A, Chuvieco E (2007) Burn severity estimation from remotely sensed data: performance of simulation versus empirical models. Remote Sensing of Environment 108, 422-435.

Giglio L, Loboda T, Roy DP, Quayle B, Justice CO (2009) An active-fire based burned area mapping algorithm for the MODIS sensor. Remote Sensing of Environment 113, 408-420.

Giglio L, Randerson JT, van der Werf GR, Kasibhatla PS, Collatz GJ, Morton DC, DeFries RS (2010) Assessing variability and long-term trends in burned area by merging multiple satellite fire products. Biogeosciences Discuss. 7, 1171-1186, doi:10.5194/bg-7-1171-2010,.

Giglio L, van der Werf GR, Randerson JT, Collatz GJ, Kasibhatla P (2005) Global estimation of burned area using MODIS active fire observations. Atmospheric Chemistry and Physics 5, 11091 11141.

González-Alonso F, Salgado, V., Calle, V., Casanova, J.L., Sanz, J., de la Fuente, D., Goldammer, J.G., Li, Z., Qin, X., Zhang, X., Deng, G., Liu, Q., Li, G., Cai, H. and Huang, Z. (2009) Forest burn in China by means of MERIS and MODIS images. Dragon 2 Symposium, June 2009, Barcelona.

Gower JFR, Borstad GA (2004) On the potential of MODIS and MERIS for imaging chlorophyll fluorescence from space. International Journal of Remote Sensing 25, 1459-1464.

Hantson S, Padilla M, Corti D, Chuvieco E (2013) Strengths and weaknesses of MODIS hotspots to characterize global fire occurrence. Remote Sensing of Environment 131, 152-159.

Huang S, Siegert F (2004) ENVISAT multisensor data for fire monitoring and impact assessment. International Journal of Remote Sensing 25, 4411-4416. 
Kachmar M, Sanchez-Azofeifa GA (2006) Detection of post-fire residuals using high- and mediumresolution satellite imagery. Forestry Chronicle 82, 177-186.

Kaufman YJ, Justice CO (1998) 'MODIS Fire products.' NASA, EOS ID\# 2741.

Kloster S, Mahowald N, Randerson J, Lawrence P (2012) The impacts of climate, land use, and demography on fires during the 21st century simulated by CLM-CN. Biogeosciences 9, 509-525.

Koutsias N, Karteris M (2000) Burned area mapping using logistic regression modeling of a single post-fire Landsat-5 Thematic Mapper image. International Journal of Remote Sensing 21, 673-687.

Martín MP, Gómez I, Chuvieco E (2005) Performance of a burned-area index (BAIM) for mapping Mediterranean burned scars from MODIS data. In 'Proceedings of the 5th International Workshop on Remote Sensing and GIS applications to Forest Fire Management: Fire Effects Assessment'. (Eds J Riva, F Pérez-Cabello and E Chuvieco) pp. 193-198. (Universidad de Zaragoza, GOFCGOLD, EARSeL: Paris)

Oliva P, Martin P, Chuvieco E (2011) Burned area mapping with MERIS post-fire image. International Journal of Remote Sensing 32, 4175-4201.

Olson DM, E. Dinerstein, et al. (2001) Terrestrial Ecoregions of the World: A New Map of Life on Earth. BioScience 51, 933-938.

Pereira JMC, Sa ACL, Sousa AMO, Silva JMN, Santos TN, Carreiras JMB (1999) Spectral characterisation and discrimination of burnt areas. In 'Remote Sensing of Large Wildfires in the European Mediterranean Basin'. (Ed. E Chuvieco) pp. 123-138. (Springer-Verlag: Berlin)

Pinty B, Verstraete MM (1992) GEMI: a non-linear index to monitor global vegetation from satellites. Vegetatio 101, 15-20.

Pu R, Gong P (2004) Determination of Burnt Scars Using Logistic Regression and Neural Network Techniques from a Single Post-Fire Landsat-7 ETM+ Image. Photogrammetric Engineering and Remote Sensing 70, 841-850.

Pu RL, Li ZQ, Gong P, Csiszar I, Fraser R, Hao W-M, Kondragunta S, Weng F (2007) Development and analysis of a 12-year daily 1-km forest fire North America from NOAA/AVHRR data. Remote Sensing of Environment 108, 198-208.

Roldan-Zamarron A, Merino-De-Miguel S, Gonzalez-Alonso F, Garcia-Gigorro S, Cuevas JM (2006) Minas de Riotinto (south Spain) forest fire: Burned area assessment and fire severity mapping using Landsat 5-TM, Envisat-MERIS, and Terra-MODIS postfire images. Journal of Geophysical Research-Biogeosciences 111.

Roy D, Jin Y, Lewis P, Justice C (2005) Prototyping a global algorithm for systematic fire-affected area mapping using MODIS time series data. Remote Sensing of Environment 97, 137-162.

Roy DP, Boschetti L, Justice CO (2008) The collection 5 MODIS burned area product - Global evaluation by comparison with the MODIS active fire product. Remote Sensing of Environment 112, 3690-3707.

Tansey K, Grégoire JM, Defourny P, Leigh R, Peckel JF, Bogaert EV, Bartholome JE (2008) A new, global, multi-annual (2000-2007) burnt area product at $1 \mathrm{~km}$ resolution. Geophysical Research Letters 35, L01401, doi:10.1029/2007GL03156.

Thonicke K, Spessa A, Prentice IC, Harrison SP, Dong L, Carmona-Moreno C (2010) The influence of vegetation, fire spread and fire behaviour on biomass burning and trace gas emissions: results from a process-based model. Biogeosciences 7, 1991-2011.

Trigg S, Flasse S (2001) An evaluation of different bi-spectral spaces for discriminating burned shrubsavannah. International Journal of Remote Sensing 22, 2641-2647.

van der Werf GR, Randerson JT, et al. (2010) Global fire emissions and the contribution of deforestation, savanna, forest, agricultural, and peat fires (1997-2009). Atmospheric Chemistry and Physics 10, 11707-11735.

Zhang QF, Pavlic G, Chen WJ, Fraser R, Leblanc S, Cihlar J (2005) A semi-automatic segmentation procedure for feature extraction in remotely sensed imagery. Computers \& Geosciences 31, 289296. 